\title{
Intractable duodenal ulcer caused by transmural migration of gossypiboma into the duodenum - a case report and literature review
}

\author{
Yun-Xiao Lv' ${ }^{1}$ Cheng-Chan $\mathrm{Yu}^{2 *}$, Chun-Fang Tung ${ }^{3}$ and Cheng-Chung $\mathrm{Wu}^{2}$
}

\begin{abstract}
Background: Gossypiboma is a term used to describe a mass that forms around a cotton sponge or abdominal compress accidentally left in a patient during surgery. Transmural migration of an intra-abdominal gossypiboma has been reported to occur in the digestive tract, bladder, vagina and diaphragm. Open surgery is the most common approach in the treatment of gossypiboma. However, gossypibomas can be extracted by endoscopy while migrating into the digestive tract. We report a case of intractable duodenal ulcer caused by transmural migration of gossypiboma successfully treated by duodenorrhaphy. A systemic literature review is provided and a scheme of the therapeutic approach is proposed.
\end{abstract}

Case presentation: A 61-year-old Han Chinese man presented with intermittent epigastric pain for the last 10 months. He had undergone laparoscopic cholecystectomy conversion to open cholecystectomy for acute gangrenous cholecystitis 10 months ago at another hospital. Transmural migration of gossypiboma into the duodenum was found. Endoscopic intervention failed to remove the entire gauze, and duodenal ulcer caused by the gauze persisted. Surgical intervention was performed and the gauze was removed successfully. The penetrated ulcer was repaired with duodenorrhaphy. The postoperative period was uneventful.

We systematically reviewed the literature on transmural migration of gossypiboma into duodenum and present an overview of published cases. Our PubMed search yielded seven reports of transmural migration of retained surgical sponge into the duodenum. Surgical interventions were necessary in two patients.

Conclusion: Transmural migration of gossypiboma into the duodenum is a rare surgical complication. The treatment strategies include endoscopic extraction and surgical intervention. Prompt surgical intervention should be considered for emergent conditions such as active bleeding, gastrointestinal obstruction, or intra-abdominal sepsis. For non-emergent conditions, surgical intervention could be considered for intractable cases in which endoscopic extraction failed.

Keywords: Gossypiboma, Duodenal ulcer, Transmural migration, Surgical complication, Duodenorrhaphy, Endoscopy, Endoscopic extraction

\section{Background}

Gossypiboma is a term used to describe a mass that forms around a cotton sponge or abdominal compress accidentally left in a patient during surgery. Transmural migration of an intra-abdominal gossypiboma has been reported to occur in the stomach, duodenum, ileum, colon, bladder, vagina and diaphragm [1-3]. Open surgery is the

\footnotetext{
* Correspondence: jefferyu@gmail.com

${ }^{2}$ Department of Surgery, Taichung Veterans General Hospital, 1650 Taiwan Boulevard Sect. 4, Taichung, Taiwan

Full list of author information is available at the end of the article
}

most common approach in the treatment of gossypiboma. However, gossypibomas can be extracted by endoscopy while migrating into the digestive tract. We report a case of intractable duodenal ulcer caused by transmural migration of gossipyboma successfully treated by duodenorrhaphy. We systematically reviewed the literature on transmural migration of gossypiboma into duodenum and present an overview of published cases. A scheme of the therapeutic approach is also proposed. 


\section{Case presentation}

A 61-year-old Han Chinese man presented with intermittent epigastric pain for the last 10 months. The pain was mild and non-radiating, without specific relieving or aggravating factors. The patient had no history of nausea, vomiting, general weakness, poor appetite or body weight loss. He had undergone laparoscopic cholecystectomy conversion to open cholecystectomy for acute gangrenous cholecystitis 10 months ago at another hospital. Gauze retention in the peritoneal cavity with migration into the duodenum was noted after upper gastrointestinal (UGI) endoscopy (Figure 1). An abdominal X-ray examination showed the retained material was a surgical sponge (Figure 2). Abdominal computed tomography (CT) scan showed transmural migration of the gauze into the duodenum (Figure 3). Endoscopic intervention failed to remove the entire gauze, and intractable duodenal ulcer caused by the gauze persisted. Surgical intervention was then performed. During the operation, a gossypiboma, about $2 \mathrm{~cm}$ in size, was noted between the supra-duodenal region and round ligament (Figure 4), with penetration into the anterior wall of the duodenal bulb, resulting in a penetrated duodenal ulcer about $1.5 \mathrm{~cm}$ in diameter (Figure 5). The gauze was embedded in the granulation tissue surrounding the gossypiboma (Figure 6). The gauze was removed successfully, and the penetrated ulcer was repaired with duodenorrhaphy. The postoperative period was uneventful.

\section{Literature search}

We searched the PubMed (2000-2013) database for case reports about transmural migration of gossypiboma into the duodenum. The abstracts of all articles published in Dutch, English, French, German, and Spanish were screened. The full texts of articles published in other languages but with an abstract in English were analyzed. Articles were selected for review if they included the

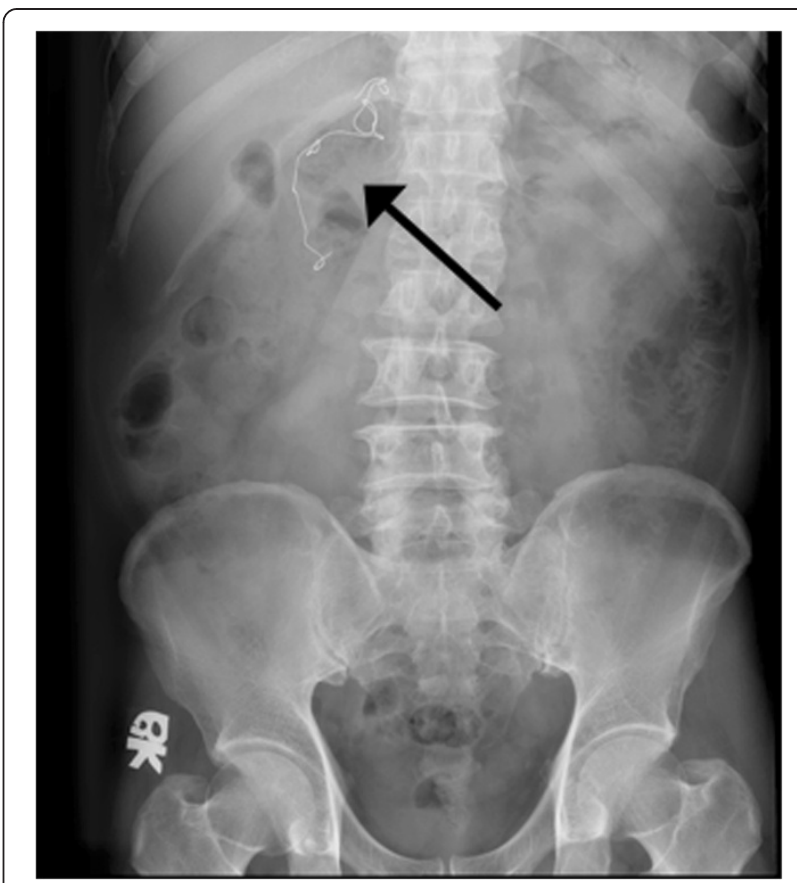

Figure 2 The plain film radiograph. Plain abdominal X-ray shows a retained surgical gauze (black arrow) in the abdominal cavity.

following patient data: age, sex, initial surgery, interval, clinical presentation, diagnostic methods, location, and surgical procedures.

\section{Results}

Our PubMed search yielded seven reports of transmural migration of retained surgical sponge into the duodenum. Relevant data are shown in Table 1. Three patients were male and four patients were female, with ages ranging from 26 to 62 years. The time from the causative operation to presentation with a retained surgical sponge ranged from 2 months to 2 years. Initial surgical procedures included cholecystectomy in 4 patients [ 5 patients, if the

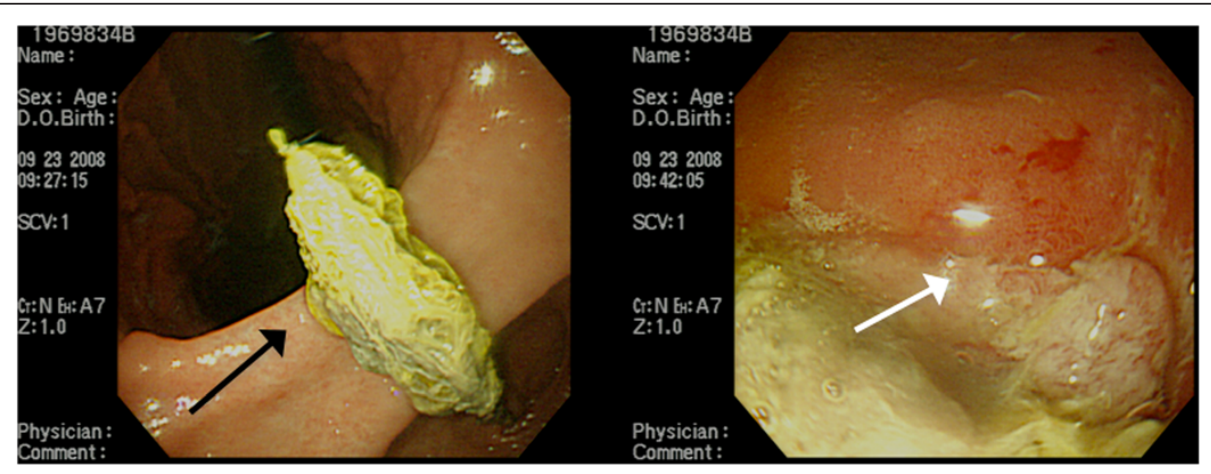

Figure 1 Endoscopic findings of the duodenum. Endoscope shows a sponge in the duodenum (black arrow) and the white-based ulcer around the gauze (white arrow). 


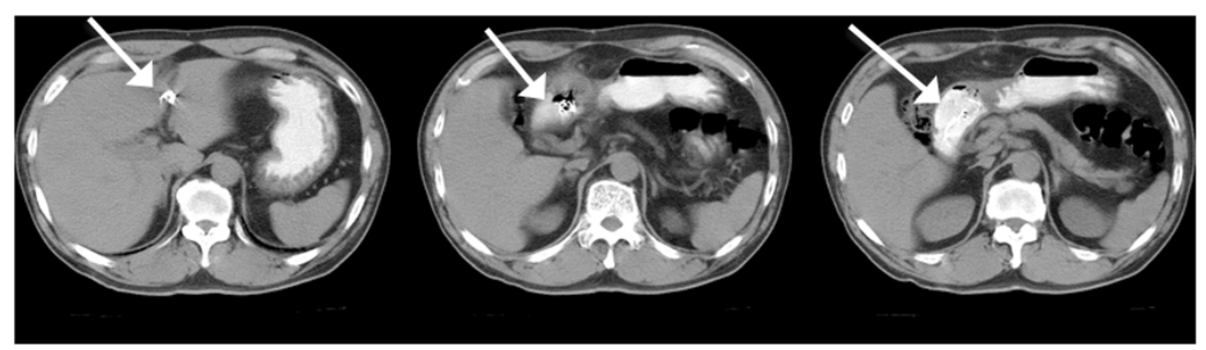

Figure 3 Abdominal CT scan. The CT-scan reveals transmural migration of the gauze into the duodenum (white arrow).

present case is included], laparotomy in 1 , hemicolectomy in 1, and removal of hydatid cyst in 1 patient. Including our case, 3 cases were scheduled for open surgery. The other 4 patients were scheduled for endoscopy to remove the gossypiboma. One patient received endoscopy but the gauze could not be retrieved using biopsy forceps and a polypectomy snare. As there was no free perforation, conservative treatment was applied, and proton pump inhibitors and liquid diet were recommended. The patient had a stable clinical course and was endoscopically followed up at 5-day intervals.

\section{Discussion}

The term "gossypiboma" denotes a cotton sponge that is retained inside a patient during surgery. The reported incidence of gossypiboma varies between $1 / 100$ and $1 /$ 3000 for all surgical interventions and from $1 / 1000$ to $1 /$ 1500 for intra-abdominal operations [9-18]. There are no national or local registers, and the reluctance of medical institutions to publish matters that may have medicolegal implications probably leads to underreporting of

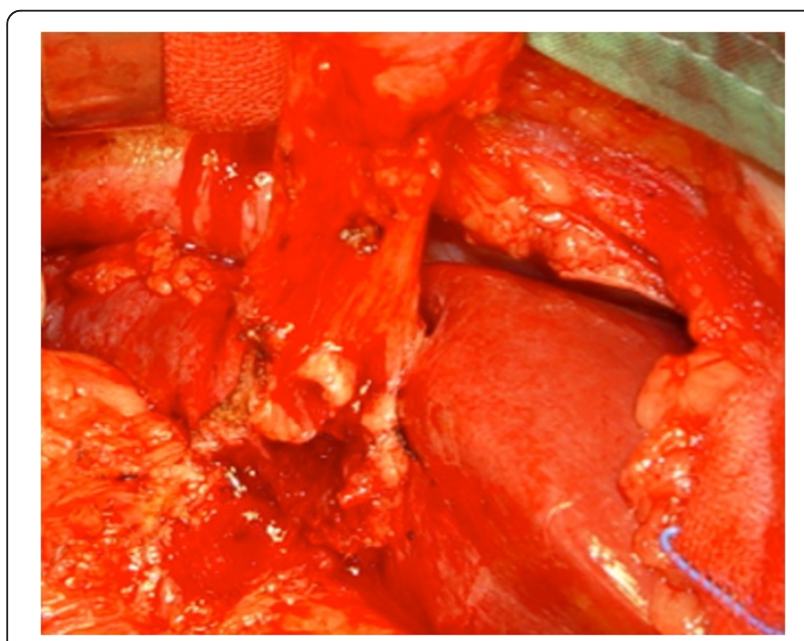

Figure 4 The intra-operative finding before removing the gossypiboma. Gossypiboma, about $2 \mathrm{~cm}$ in size, was noted between the supra-duodenal region and round ligament. diagnosed cases. Furthermore, some patients remain asymptomatic and in such cases gossypibomas may never be found.

As a consequence of gossypiboma, two types of foreign body reactions can occur. The first type is an aseptic fibrous response to the foreign material that creates adhesions and encapsulation. The result is a foreign body granuloma which may take a silent clinical course which dose not produce any clinical symptoms. A gossypiboma may undergo calcification, disruption, partial absorption, and even diffusion. The second type of foreign body reaction is exudative in nature and produces an inflammatory reaction with abscess formation. The body attempts to extrude the foreign material, which may lead to post-surgical complications such as external fistula formation or erosion and perforation into adjacent viscera. This may then result in migration of the foreign body into the gut, intestinal obstruction, or extrusion of the sponge through the rectum. The exudative type of response often causes symptoms in

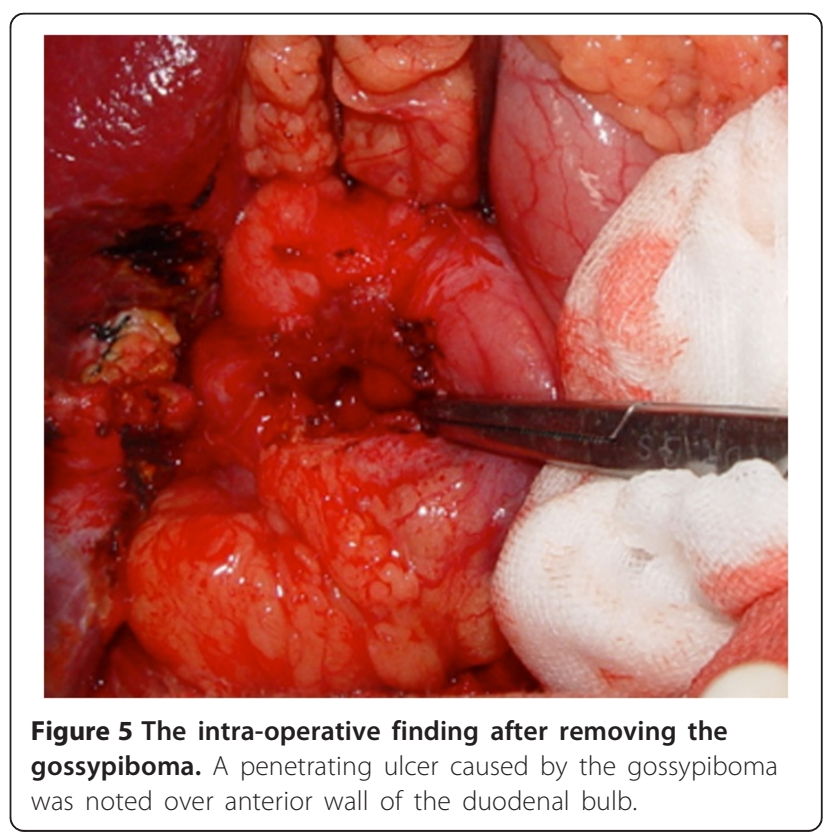




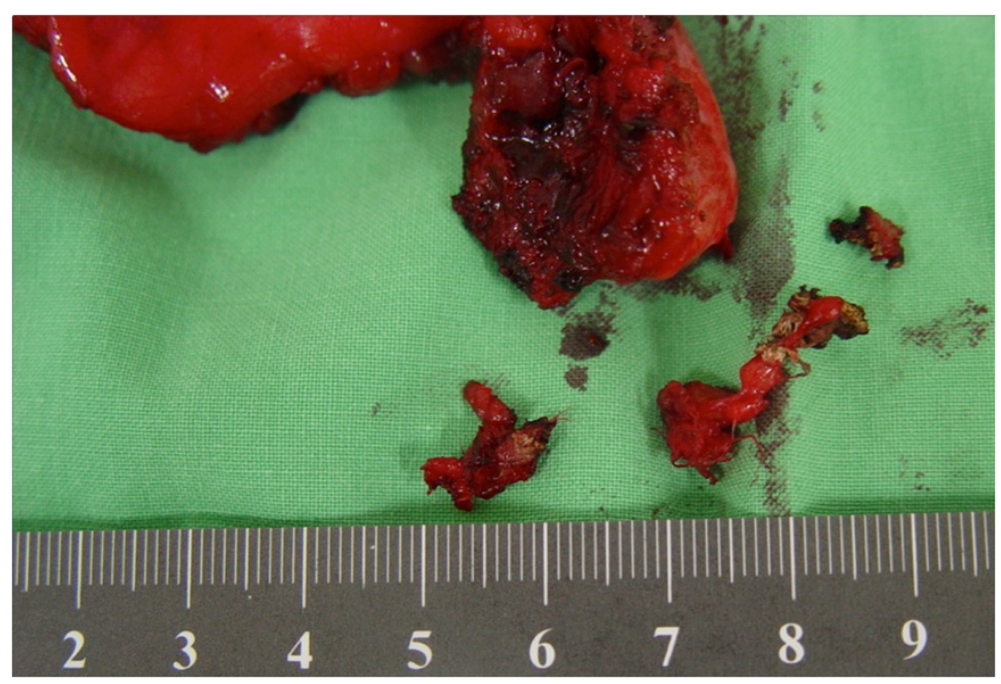

Figure 6 The removed specimen. The gauze was embedded in the granulation tissue surrounding the gossypiboma.

the early postoperative period, but the extrusion process may take years and the clinical symptoms are unspecific [7-9,19-25]. Wattanasirichaigoon describes 4 stages in the process of migration: foreign body reaction, secondary infection, mass formation, and remodeling [25].

According to the literature, transmural migration of gossypiboma into the duodenum is rare. To date, only 7 cases have been published [2,4-8,26]. Other reported sites of migration include seven sponges into the jejunum, five into the stomach, five into the colon, one into the ileocolic region, one into the ileojejunal region, and one into both the jejunum and colon. In three patients, the surgical sponge passed spontaneously through the rectum. The small intestine is the most common part of the intestine into which migration takes place (Table 2). The most common initial surgery for removal of gossypiboma in the gastrointestinal system was cholecystectomy (15 cases), followed by caesarian section (9 cases), hysterectomy (7 cases), laparotomy (5 cases), appendectomy (3 cases), splenectomy (1 case), distal gastrectomy (1 case), hemicolectomy (1 case), cystectomy + myomectomy (1 case), hydatid cyst (1 case), nephrectomy (1 case) and anterior resection (1 case) (Table 3$)$.

Many risk factors, such as duration and complexity of surgery, excessive blood loss in trauma patients, surgery under emergency conditions, unplanned procedural changes, a change in operating room teams during the course of the operation, and a failure to count surgical instruments and sponges, were identified. The

Table 1 Transmural migration of gossypiboma into the duodenum: review of the selected literature (2000-2013)

\begin{tabular}{|c|c|c|c|c|c|}
\hline References & Initial surgery & $\begin{array}{l}\text { Interval } \\
\text { (months) }\end{array}$ & Clinical presentation & Diagnosis methods & Interventions (Surgical indication) \\
\hline Erdil et al. [2] & Cholecystectomy & 12 & Gl bleeding & US,ERCP & Endoscopic extraction \\
\hline Sinha et al. [4] & Laparotomy & 12 & Abdominal pain & US, CT, endoscopy & Endoscopic extraction \\
\hline Alis et al. [5] & Hydatid cyst & 2 & Abdominal pain & Endoscopy, CT & Spontaneously expelled \\
\hline $\begin{array}{l}\text { Peyrin-Biroulet } \\
\text { et al. [6] }\end{array}$ & Left, Hemicolectomy & 6 & Vomiting & Endoscopy, CT & Endoscopic extraction \\
\hline Sarda et al. ${ }^{7}$ & Cholecystectomy & 2 & $\begin{array}{l}\text { Abdominal pain, } \\
\text { vomiting }\end{array}$ & Endoscopy & Endoscopic extraction \\
\hline Dux et al. [7] & Cholecystectomy & 10 & $\begin{array}{l}\text { Abdominal pain, } \\
\text { vomiting }\end{array}$ & $\mathrm{CT}$ & Surgical drainage (Persistent duodenal fistula) \\
\hline Manikyam et al. [8] & Cholecystectomy & 24 & $\begin{array}{l}\text { Abdominal pain, } \\
\text { vomiting }\end{array}$ & US, Endoscopy & $\begin{array}{l}\text { Right hemicolectomy, Duodenorraphy } \\
\text { (Gastric outlet obstruction and } \\
\text { duodeno-ileo-colic fistula) }\end{array}$ \\
\hline $\begin{array}{l}\text { Lv et al. } \\
\text { (present study) }\end{array}$ & Cholecystectomy & 10 & Abdominal pain & Endoscopy CT & $\begin{array}{l}\text { Endoscopic extraction, Duodenorrhaphy } \\
\text { (Intractable duodenal ulcer) }\end{array}$ \\
\hline
\end{tabular}


Table 2 Reported cases of transmural migration of gossypiboma into the gastrointestinal organs according to the impacted gastrointestinal organs: review of the selected literature (2000-2013)

\begin{tabular}{lcl}
$\begin{array}{l}\text { The impacted } \\
\text { gastrointestinal organs }\end{array}$ & $\begin{array}{c}\text { No. of } \\
\text { patients }\end{array}$ & References \\
\hline Stomach & 5 & {$[9,19,27-29]$} \\
Duodenum & 7 & {$[2,4-8,26]$} \\
Small intestine & 23 & {$[7,9-14,19,20,27-45]$} \\
Colon & 5 & {$[15,46-49]$} \\
Small intestine and colon & 3 & {$[16,17,50]$} \\
Rectum & 3 & {$[1,18,48]$} \\
\hline
\end{tabular}

three most important risk factors are emergency surgery, unplanned change in the operation, and body mass index $[2,15,18,33]$.

Nonspecific clinical symptoms may preclude an accurate diagnosis. The clinical presentation of gossypiboma is variable. According to the literature, common symptoms and signs of transmural migration of gossypiboma into the duodenum may include abdominal pain, vomiting, and bleeding $[7,9,30]$. The most frequently reported symptom was abdominal pain. The main complications of abdominal gossypiboma were bowel or viscera perforation, obstruction, peritonitis, adhesion, abscess development, fistula formation, sepsis, and migration of the sponge into the lumens of the gastrointestinal tract $[9,30]$.

The diagnosis of gossypiboma is difficult because the clinical symptoms are nonspecific and the imaging

Table 3 Reported cases of transmural migration of gossypiboma into the gastrointestinal organs according to the initial procedures: review of the selected literature (2000-2013)

\begin{tabular}{lcl}
\hline Initial procedures & $\begin{array}{c}\text { No. of } \\
\text { patients }\end{array}$ & References \\
\hline Cholecystectomy & 15 & {$[2,7,8,12,14,19,27,29,30,36-39,43,47]$} \\
Caesarian section & 9 & {$[1,13,17,32-34,40,48,50]$} \\
Hysterectomy & 7 & {$[11,16,18,20,26,42,45]$} \\
Laparotomy & 5 & {$[4,15,20,44,49]$} \\
Appendectomy & 3 & {$[10,35,46]$} \\
Splenectomy & 1 & {$[12]$} \\
Distal Gastrectomy & 1 & {$[9]$} \\
Hemicolectomy & 1 & {$[6]$} \\
Cystectomy + & 1 & {$[41]$} \\
Myomectomy & & \\
Hydatid cyst & 1 & {$[5]$} \\
Nephrectomy & 1 & {$[28]$} \\
Anterior resection & 1 & {$[28]$} \\
\hline
\end{tabular}

findings are often inconclusive. In imaging studies, they are mostly seen as radio-opaque material, yet radiolucent material like sponges can cause diagnostic problems. However, plain radiography, barium studies, endoscopy, ultrasonography (US), CT, and magnetic resonance imaging (MRI) are useful for diagnosis [17]. Plain radiographs may disclose the presence of gossypiboma if the surgical sponge is calcified or when a characteristic "whirl-like" pattern is evident. In the literatures, endoscopy played an important role in the diagnosis and treatment of intraluminal gossypiboma cases.

Gossypibomas should be removed as soon as diagnosed. Surgery is the preferred method of treatment for gossypiboma. Various techniques, including percutaneous techniques, such as laparoscopy and laparotomy, are used for the removal of gossypiboma, depending on the clinical presentation and medical equipment available $[4,6,26,30,46]$. In cases with migration of gossypiboma into the digestive tract, nonsurgical approaches such as endoscopic retrieval of foreign bodies have been reported. According to the literature, gastrostomy, segmental resection, and endoscopic extraction were used for removal of gossypibomas that migrated into the stomach, intestine and colon, and duodenum, respectively. For patients with gossypiboma transmurally migrated into duodenum, endoscopic removal could be attempted if there was no emergent conditions such as active GI bleeding, obstruction, or free perforation. Of the eight cases of gossypiboma migrated into duodenum, including our case, surgical intervention was necessary in three patients for persistent fistula or intractable ulcer. If the endoscopy fails to retrieve the gossypiboma and the patient is asymptomatic, conservative treatment with close observation can be considered. A therapeutic scheme is proposed for the treatment of gossypiboma transmurally migrated into the digestive tract (Figure 7).

\section{Conclusion}

In conclusion, gossypiboma should be considered in the differential diagnosis of any postoperative patient who presents with pain, infection, or a palpable mass. Plain radiography, barium studies, endoscopy, ultrasonography, CT scan, and MRI are useful for diagnosis. Transmural migration of gossypiboma into the duodenum is a rare surgical complication. The treatment strategies include endoscopic removal and surgical intervention. Prompt surgical intervention should be considered for emergent conditions such as active bleeding, GI obstruction, or intra-abdominal sepsis. For non-emergent conditions, surgical intervention could be considered in intractable cases if endoscopic extraction failed. 


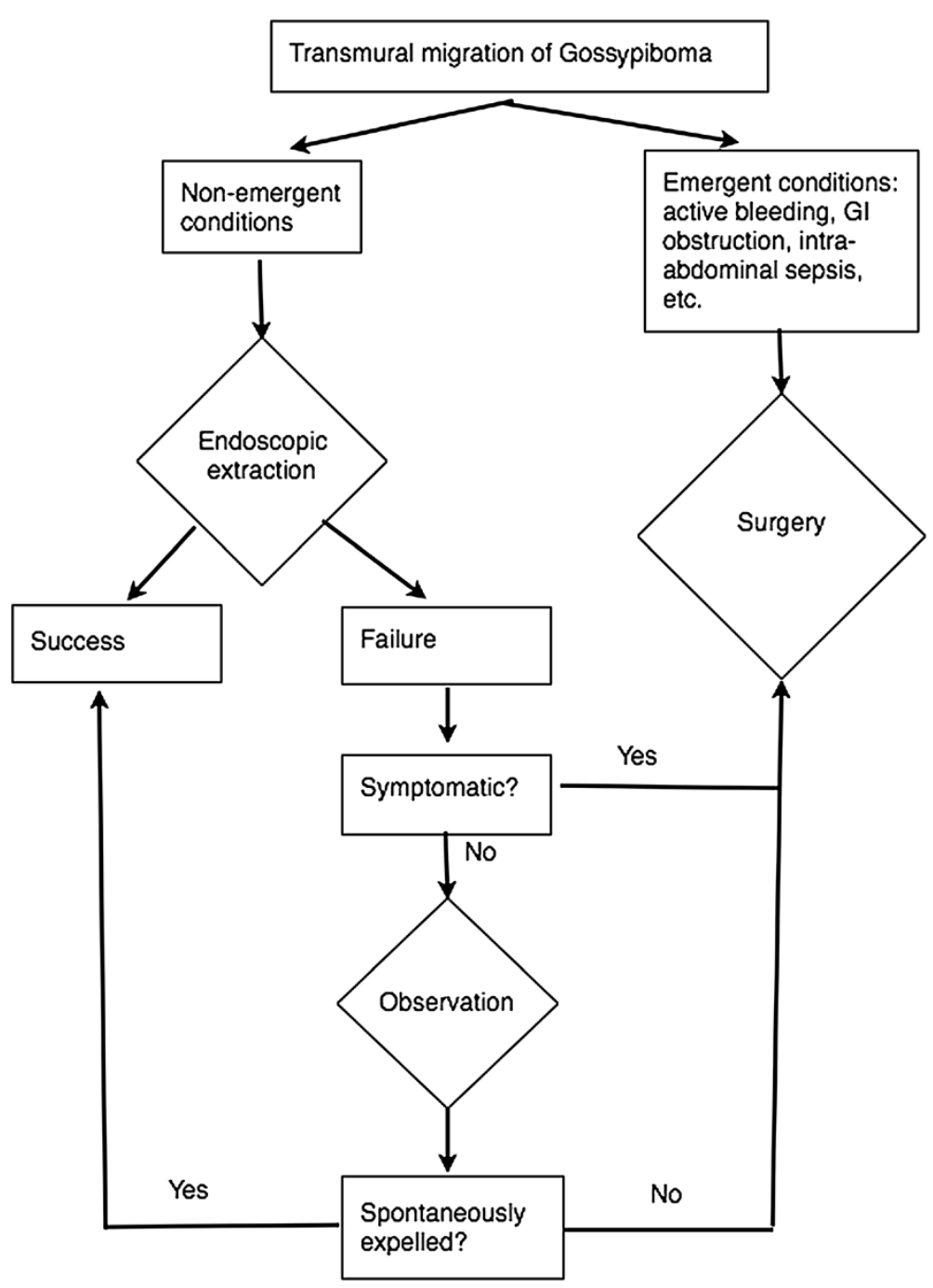

Figure 7 Scheme of the therapeutic approach proposed for transmural migration of gossypiboma into gastrointestinal system. For patients with gossypiboma transmurally migrated into gastrointestinal system, endoscopic removal could be attempted if there was no emergent conditions such as active Gl bleeding, obstruction, or intra-abdominal sepsis. If the endoscopy fails to retrieve the gossypiboma and the patient is symptomatic, surgical intervention is indicated. For asymptomatic patients after unsuccessful endoscopic extraction, conservative treatment with close observation can be considered.

\section{Consent}

Written informed consent was obtained from the patient for publication of this Case report and any accompanying images. A copy of the written consent form is available for review by the Editor of this journal.

\section{Abbreviations}

UGI: Upper Gastrointestinal; CT: Computed Tomography; US: Ultrasound; MRI: Magnetic resonance imaging; ERCP: Endoscopic retrograde cholangiopancreatography.

\section{Competing interests}

The authors declare that they have no competing interests.

\section{Authors' contributions}

YXL searched the literatures and drafted the manuscript. CCY conceived of the study, participated in its design and coordination, and final revision of the manuscript. CFT participated in the collection of the clinical data and design of the study. CCW participated in the design of the study and critical revision of the manuscript. All authors read and approved the final manuscript.

\section{Acknowledgement}

The authors thanks the Department of Medical Research, Taichung Veterans General Hospital for providing the funding for English language editing.

\section{Author details}

${ }^{1}$ Department of Hepatobiliary Surgery, Dongyang People's Hospital, No60, West Wuning Road, Dongyang, Jinhua, Zhejiang, China. 'Department of Surgery, Taichung Veterans General Hospital, 1650 Taiwan Boulevard Sect. 4, Taichung, Taiwan. ${ }^{3}$ Department of Internal Medicine, Taichung Veterans General Hospital, 1650 Taiwan Boulevard Sect. 4, Taichung, Taiwan.

Received: 24 December 2013 Accepted: 5 June 2014

Published: 10 June 2014 


\section{References}

1. Zantvoord $Y$, Weiden RM, van Hooff MH: Transmural migration of retained surgical sponges: a systemic review. Obstet Gynecol Surv 2008, 63(7):465-471.

2. Erdil A, Kilciler G, Ates Y, Tuzun A, Gulsen M, Karaeren N, Dagalp K: Transgastric migration of retained intraabdominal surgical sponge: gossypiboma in the bulbus. Inter Med 2008, 47(7):613-615.

3. Lin TY: Chuang CK:Gossypiboma: migration of retained surgical gauze and spontaneous transurethral protrusion. BJU Int 1999, 84(7):879-880

4. Sinha SK, Udawat HP, Yadav TD, Lal A, Rana SS: Bhasin DK:Gossypiboma diagnosed by upper-Gl endoscopy. Gastrointest Endosc 2007, 65:347-349.

5. Alis H, Soylu A, Dolay K, Kalacyci M, Ciltas A: Surgical intervention may not always be required in gossypiboma with intraluminal migration. World J Gastroenterol 2007, 13(48):6605-6607.

6. Peyrin-Biroulet L, Oliver A: Bigard MA:Gossypiboma successfully removed by upper-Gl endoscopy. Gastrointest Endosc 2007, 66(6):1251-1252.

7. Dux M, Ganten M, Lubienski A, Grenacher L: Retained surgical sponge with migration into the duodenum and persistent duodenal fistula. Eur Radiol 2002, 12(suppl 3):S74-S77.

8. Manikyam SR, Gupta V, Gupta R, Gupta NM: Retained surgical sponge presenting as a gastric outlet obstruction and duodeno-ileo-colic fistula: report of a case. Surg Today 2002, 32:426-428.

9. Yildirim S, Tarim A, Nursal TZ, Yildirim T, Caliskan K, Torer N, Karagulle E, Noyan T, Noyan T, Moray G, Haberal M: Retained surgical sponge (gossypiboma) after intraabdominal or retroperitoneal surgery: 14 cases treated at a single center. Langenbecks Arch Surg 2006, 391(4):390-395.

10. Bani-Hani KE, Gharaibeh KA, Yaghan RJ: Retained surgical sponges (gossypiboma). Asian J Surg 2005, 28:109-115.

11. De Campos FF, Franco F, Maximiano LF, Martines JA, Felipe-silva AS, Kunitake TA: An iron deficiency anemia of unknown cause: a case report involving gossypiboma. Clinics (Sao Paulo) 2010, 65(5):555-558.

12. Akbulut S, Sevinc MM, Basak F, Aksory S, Cakabay B: Transmural migration of a surgical compress into the stomach after splenectomy: a case report. Cases J 2009, 2:7975.

13. Patil KK, Patil SK, Gorad KP, Panchal AH, Arora SS, Gautam RP: Intraluminal migration of surgical sponge: gossypiboma. Saudi J Gastroenterol 2010 16(3):221-222

14. Agarwal AK, Bhattacharya N, Mukherjee R: Intraluminal gossypiboma. Pak J Med Sci 2008, 24(3):461-463.

15. Cruz RJ Jr, Poli De Figueiredo LF, Guerra L: Intracolonic obstruction induced by a retained surgical sponge after trauma laparotomy. J Trauma 2003, 55(5):989-991.

16. Gupta S, Mathur AK: Spontaneous transmural migration of surgical sponge causing small intestine and large intestine obstruction. ANZ J Surg 2010, 80(10):756-757.

17. Govarjin HM, Talebian M, Fattahi F, Akbari ME: Migration of retained long gauze from abdominal cavity to intestine. JRMS 2010, 15(1):54-57.

18. Dakubo J, Clegg-Lamptey J, Hodasi W, Obaka H, Toboh H, Asempa W: An intra-abdominal gossypiboma. Ghana Med J 2009, 43(1):43-45.

19. Tiwary SKR, Khanna R, Khanna AK: Transmural Migration of Surgical Sponge Following Cholecystectomy: An unusual cause of gastric outlet obstruction. Internet J Surg 2006, 7:2

20. Gwande AA, Studdert DM, Orav EJ, Brennan TA, Zinner MJ: Risk factors for retained instruments and sponges after surgery. N Engl J Med 2003, 348(3):229-235.

21. Mentes BB, Yilmaz E, Sen M, Kayhan B, Gorgul A, Tatlicioglu E: Transgastric migration of a surgical sponge. J Clin Gastroenterol 1997, 24(1):55-57.

22. Cheng TC, Chou AS, Jeng CM, Chang PY, Lee CC: Computed tomography findings of gossypiboma. J Chin Med Assoc 2007, 70(12):565-569.

23. Erbay G, Koc Z, Caliskan K, Araz F, Ulusan S: Imaging and clinical findings of a gossypiboma migrated into the stomach. Turk J Gastroenterol 2012, 23(1):54-57

24. Kundan KK, Patil SK, Gorad KP: Intraluminal migration of surgical sponge: gossypiboma. Saudi J Gastroenterol 2010, 16(3):221-222.

25. Wattanasirichaigoon S: Transmural migration of a retained surgical sponge into the intestinal lumen: an experimental study. J Med Assoc Thai 1996, 79:415-422.

26. Sarda AK, Pandey D, Neogi S: Dhir U:Postoperative complications due to a retained surgical sponge. Singapore Med J 2007, 48:160-164.

27. Alegre-Salles V, Saba E, Dias-Soares P: Clinical images in gastroenterology: Textiloma (Gossypiboma) in the gastric lumen. Rev Gastroenterol Mex $2010,75(1): 77$
28. Keymeulen K, Dillemans B: Epitheloid angiosarcoma of the splenic capsula as a result of foreign body tumorigenesis. Case report Acta Chir Belg 2004, 104(2):217-220.

29. Sozutek A, Yormaz S, Kupeli H, Saban B: Transgastric migration of gossypiboma remedied with endoscopic removal: a case report. BMC Res Notes 2013, 14(6):413.

30. Kansakar R, Thapa P, Adhikari S: Intraluminal migration of gossypiboma without intestinal obstruction for fourteen years. JNMA J Nepal Med Assoc 2008, 47(171):136-138.

31. Yeung KW, Chang MS, Huang JF: Imaging of transmural migration of a retained surgical sponge: a case report. Kaohsiung J Med Sci 2004, 20(11):567-571.

32. Uluçay T, Dizdar MG, Sunay Yavuz M: The importance of medicolegal evaluation in a case with intra-abdominal gossypiboma. Forensic Sci Int 2010, 198(1-3):15-18.

33. Sumer A, Carparlar MA, Uslukaya O, Bayrak V, Kotan C, Kemik O, Llikerden U: Gossypiboma: retained surgical sponge after a gynecoogic procedure. Case Report Med 2010, 917626.

34. Sarker M, Kibra G, Haque M, Sarker KP: Spontaneous transmural migration of the retained surgical mop into the small intestinal lumen causing sub-acute intestinal obstruction: a case report. TAJ 2006, 19(1):34-37.

35. Turan M, Kibar Y, Karadayi K: Intraluminal migration of retained surgical sponge without sign of peritonitis - report of a case. Chir Gastroenterol 2003, 19(2):181-183.

36. Sharma D, Pratap A, Tandon A, Shukla RC, Shukla VK: Unconsidered cause of bowel obstruction- gossypiboma. Can J Surg 2008, 51(2):34-35.

37. Grassi N, Cipolla C, Torcivia A, Bottino A, Fiorentino E, Ficano L, Pantuso G: Trans-visceral migration of retained surgical gauze as a cause of intestinal obstruction: a case report. J Med Case Rep 2008, 2:17.

38. Gencosmanoglu R, Inceoglu R: An unusual cause of small bowel obstruction: gossypiboma - case report. BMC Surg 2003, 3:6.

39. Puri SK, Panicker H, Narang P: Spontaneous transmural migration of a retained surgical sponge into the intestinal lumen-a rare cause of Intestinal obstruction. Indian J Radiol Imag 2002, 12(1):137-139.

40. Silva CS, Caetano MR, Silva EA, Falco L, Murta EF: Complete migration of retained surgical sponge into ileum without sign of open intestinal wall. Arch Gynecol Obstet 2001, 265(2):103-104.

41. Disu S, Wijesiriwardana A, Mukhtar H, Eben F: An ileal migrationof a retained surgical swab (gossypiboma): a rare cause of an epigastric mass. J Obstet Gynaecol 2007, 27(2):212-213.

42. Kato T, Yamaguchi K, Kinoshita K, Sasaki K, Kagaya H, Meguro T, Morita T, Takahashi T: Intestinal Obstruction due to Complete Transmural Migration of a Retained Surgical Sponge into the Intestine. Case Rep Gastroenterol 2012, 6(3):754-759.

43. Malhotra MK: Migration surgical gossypiboma-cause of iatrogenic perforation: case report with review of literature. Niger I Surg 2012, 18(1):27-29

44. Ogundiran T, Ayandipo O, Adeniij Sofoluwe A, Ogun G, Oyewole O, Ademola A: Gossypiboma: complete transmural migration of retained surgical sponge causing small bowel obstruction. BMJ Case Rep 2011, doi:10.1136/bcr.04.2011.4073.

45. Rappaport $W$, Haynes $K$ : The retained surgical sponge following intraabdominal surgery. Continuing Problem Arch Surg 1990, 125(3):405-407.

46. Hinrichs C, Methratta S, Ybasco AC: Gossypiboma treated by colonoscopy. Pediatr Radiol 2003, 33(4):261-262.

47. Ozyer U, Boyvat F: Imaging of a retained laparotomy towel that migrated into the colon lumen. Indian J Radiol Imaging 2009, 19(3):219-221.

48. Choi JW, Lee CH, Kim KA, Park CM, Kim JY: Transmural migration of surgical sponge evacuated by defecation: mimicking an intraperitoneal gossypiboma. Korean J Radiol 2006, 7:212-214.

49. Reichelt A, Buchholz G, Schülke C: Migration of a retained intra-abdominal foreign body into the colon. Chirurg 2011, 82(11):1027-1030

50. Tandon A, Bhargava SK, Gupta A, Bhatt S: Spontaneous transmural migration of retained surgical textile into both small and large bowel: a rare cause of intestinal obstruction. Br J Radiol 2009, 82(976):72-75.

doi:10.1186/1471-2482-14-36

Cite this article as: Lv et al:: Intractable duodenal ulcer caused by transmural migration of gossypiboma into the duodenum - a case report and literature review. BMC Surgery 2014 14:36. 